ARTICLE OPEN

\title{
The prevalence of antinuclear antibodies in patients with schizophrenia spectrum disorders: results from a large cohort study
}

\author{
Hans C van Mierlo ${ }^{1}$, Lot de Witte ${ }^{1}$, Ronald HWM Derksen ${ }^{2}$, Henny G Otten ${ }^{3}$ and the GROUP investigators ${ }^{4}$
}

BACKGROUND: An increased prevalence of autoantibodies has been found in patients with schizophrenia, suggesting a role for autoimmunity in schizophrenia pathogenesis.

METHODS: We examined the presence of antinuclear antibodies (ANAs), with further determination of specific antibodies, in 368 patients with a schizophrenia spectrum disorder and 283 healthy controls.

RESULTS: No significant difference in prevalence of ANAs between patients (8\%) and controls (11\%) was found.

CONCLUSION: We did not find an association between ANAs and schizophrenia spectrum disorders. We discuss potential reasons for the discrepancy with some previous studies, such as inclusion of patients using chlorpromazine, which can induce ANAs.

npj Schizophrenia (2015) 1, Article number: 15013; doi:10.1038/npjschz.2015.13; published online 6 May 2015

\section{INTRODUCTION}

Several lines of evidence suggest that the immune system is involved in the etiopathology of schizophrenia. This theory is supported by the findings of an increased prevalence of autoimmune diseases among patients with schizophrenia ${ }^{1}$ and a higher frequency of several autoantibodies in the blood of patients with schizophrenia, as shown by a recent systematic review, ${ }^{2}$ including antinuclear antibodies (ANAs). The presence of ANAs is used to support the clinical diagnosis of various autoimmune disorders and can be seen as a marker of autoimmunity. ${ }^{3}$

Ezeoke et al. ${ }^{2}$ concluded that ANAs are significantly more prevalent in patients with schizophrenia as compared with controls (22.2 vs. 6.7\%). The authors, however, mention that there is a marked heterogeneity and inconsistency among included studies and that additional studies are needed that control for potential confounding factors, such as clinical status, age, genetic background, and medication.

ANAs are autoantibodies that react with intracellular components ${ }^{4}$ and can be further divided into antibodies directed against double-stranded DNA or specific proteins such as SSA., Examples of autoimmune diseases with a high prevalence of ANAs (up to 93\%) are systemic lupus erythematosus, systemic sclerosis, Sjögren's syndrome, mixed connective tissue disease, inflammatory myopathies, and some autoimmune hepatic disorders. ${ }^{7-9}$ However, ANAs are also frequently found in the general population with an estimated prevalence ranging from 1 to $20 \%$. The wide range in reported prevalence is caused, among others, by differences in assays used, cutoff values used for a positive result and characteristics of the studied population. The prevalence of ANAs is higher in females than in males and increases with age. ${ }^{10}$

The aim of this study was to examine the prevalence of ANAs among patients with a schizophrenia spectrum disorder as compared with healthy controls and to subsequently analyze the presence of specific antibodies in participants testing positive for ANAs. Previous studies in patients with schizophrenia spectrum disorders often consisted of small cohorts; the present study is one of the largest case-control studies to date-it includes the most important confounding factors and does not include patients on chlorpromazine medication that can induce ANAs.

\section{MATERIALS AND METHODS}

Data collection

The data from this study were collected as part of the ongoing multicenter longitudinal Genetic Risk and Outcome of Psychosis (GROUP) study, started in The Netherlands in 2006. ${ }^{11}$ This study was approved by the human ethics committees of the University Medical Centers of Utrecht, Amsterdam, Maastricht and Groningen. All included patients and healthy volunteers provided written informed consent before participating.

This study consists of 368 patients and 283 healthy controls whose plasma samples were available for analysis. Plasma samples were collected during a follow-up visit in 2009.

\section{Population}

Patients were recruited from mental health centers throughout the Netherlands in 2006. Healthy controls were recruited via mailings to random addresses in the catchment region. Inclusion criteria for patients were: fluent in Dutch and diagnosis of a schizophrenia spectrum disorder at follow-up according to the Comprehensive Assessment of Symptoms and History $(\mathrm{CASH})^{12}$ or Schedules for Clinical Assessment in Neuropsychiatry $(\mathrm{SCAN})^{13}$ interview. Eligible healthy controls had to meet the following criteria: fluent in Dutch, no history of a lifetime psychotic disorder or lithium use and no first- or second-degree family member with a lifetime psychotic disorder. All subjects with a psychosis due to a general medical condition were excluded from this study. Data on current or previous comorbid physical disorders were collected through questionnaires.

\footnotetext{
${ }^{1}$ Department of Psychiatry, Brain Center Rudolf Magnus, University Medical Center Utrecht, Utrecht, The Netherlands; ${ }^{2}$ Department of Rheumatology and Clinical Immunology, University Medical Center Utrecht, Utrecht, The Netherlands and ${ }^{3}$ Laboratory of Translational Immunology, University Medical Center Utrecht, Utrecht, The Netherlands. Correspondence: HC van Mierlo (h.vanmierlo@umcutrecht.nl)

${ }^{4}$ The members of Genetic Risk and Outcome of Psychosis (GROUP) Investigators are listed before references.

Received 22 December 2014; revised 30 January 2015; accepted 3 February 2015
} 
Plasma analysis

Blood was drawn by venous puncture and after centrifugation plasma samples were stored in $-80^{\circ} \mathrm{C}$ until further analysis.

Plasma samples from all participants were tested for ANAs by indirect immunofluorescence using a commercially available assay, according to the manufacturer's protocol (Euroimmun, Lübeck, Germany). In short, plasma samples were diluted 1:100 and incubated with HEp-20-10 cells and primate liver substrates. After washing, attached antibodies were stained using a fluorescein-labeled antibody against human IgG. Nuclear staining was evaluated by two independent raters unaware of subject status and rated negative (absent or weak staining) or positive (moderate or strong staining). Subsequently, ANA-positive samples were examined for specific antibodies using a commercially available line blot assay according to the manufacturer's protocol (Profile 3 line blot, Euroimmun, Lübeck, Germany). In brief, plasma samples were diluted 1:101 and incubated on a membrane strip containing 14 antigen extracts (histones, nucleosomes, double-stranded DNA, PCNA, centromere protein $\mathrm{B}, \mathrm{PM} / \mathrm{SCl}$ Scl-70, SSB, SSA, Sm, nRNP, mitochondrial M2, ribosomal-P and Jo-1). Subsequently, the strips were stained using an alkaline phosphataselabeled anti-human IgG antibody, which was visualized by an NBT/BCIP substrate solution. Assayses were interpreted using the scanning software (Euroimmun, Lübeck, Germany) provided by the manufacturer.

\section{Statistical analysis}

Differences in baseline characteristics between the two diagnostic groups were examined using $X^{2}$ and Mann-Whitney $U$-tests when appropriate. To assess whether the prevalence of ANAs was significantly different between the group of patients and the control subjects $X^{2}$-tests were used. $A$ multiple logistic regression model was used to examine the influence of diagnostic group, gender, age, and ethnicity on ANA status.

\section{RESULTS}

Table 1 shows an overview of the characteristics of both patient and control subjects. In total, 29 patients (8\%) and 32 controls (11\%) tested positive for ANAs. This difference was not significant: $X^{2}=2.212, P=0.137$. The ANA assay was strongly positive in $6 / 29$ (21\%) patients and $7 / 32(22 \%)$ control subjects.

Age, ethnicity, and gender have previously been shown to be associated with ANAs. In our study, significantly more patients compared with control subjects were male $(76 \%$ of the patients versus $42 \%$ of the control subjects). When we analyzed both gender groups separately, 21 out of 281 male patients (7\%) and 11 out of 118 male control subjects (9\%) tested positive for ANAs $\left(X^{2}=0.385, P=0.535\right)$, whereas in the group of females 8 out of 87 patients $(9 \%)$ and 21 out of 165 controls (13\%) tested positive for ANAs $\left(X^{2}=0.698, P=0.404\right)$.
Using multiple logistic regression analysis, we did not find a significant influence of age, gender, or ethnicity on ANA status (data not shown).

To assess the potential influence of antipsychotics on the ANA status, we examined the prevalence of ANAs in the group of patients currently using antipsychotics $(N=257)$ as compared with the group of patients currently not using antipsychotics $(N=37)$. The prevalence of ANAs was $6 \%$ and $8 \%$, respectively (no significant difference: $X^{2}=0.190, P=0.663$ ). Furthermore, we found no significant difference in the prevalence of ANAs between patients currently using first $(N=24)$ and second generation $(N=183)$ antipsychotic agents $\left(X^{2}=0.206, P=0.650\right)$.

All 61 samples that tested positive for ANAs (29 originating from patients and 32 from control subjects), were tested for specificity in a line blot assay. In total, eight samples had a positive line blot result against the following antigens: histone, pCNA, SSA, and a mitochondrial antigen. Positive results were equally distributed among patients and control subjects (Table 1).

\section{DISCUSSION}

Previous studies have not shown an unambiguous relation between ANAs and schizophrenia spectrum disorders (Table 2). Recognized reasons for contradictory results are differences in the techniques used to detect ANAs, differences in definition of positive results, variation and shortcomings in studied populations and whether or not control subjects were included. ${ }^{2}$

We found a similar prevalence of ANAs in patients with a schizophrenia spectrum disorder and control subjects, using indirect immunofluorescence on HEp-2 cells to detect ANAs, which is the gold standard for their detection. ${ }^{3}$ Many published studies consisted of small cohorts and did not include a control group. An overview of previous case-control studies is provided in Table 2. Furthermore, most studies did not correct for gender and age. $^{2}$ The present study does not suffer from these shortcomings.

Another important reason for the discrepant results in studies on ANA frequencies can be the use of medication. Various earlier studies have included a large proportion of patients using chlorpromazine $^{14-18}$ or did not describe medication use. Chlorpromazine is known to induce ANAs. ${ }^{19,20}$ None of the patients included in our study were on chlorpromazine as this drug is not available in the Netherlands since $2008{ }^{21}$ unfortunately, we cannot exclude that some of the included patients might have used chlorpromazine before 2008 .

Table 1. Characteristics of patients and controls

\begin{tabular}{|c|c|c|c|}
\hline & Patients $(\mathrm{N}=368)^{\mathrm{a}}$ & Controls $(\mathrm{N}=283)$ & Group comparison test \\
\hline Gender M/F (\%males) & $281 / 87(76 \%)$ & 118/165 (42\%) & $P<0.01$ \\
\hline Mean age (SD) in years & $30.5( \pm 7.0)$ & $34.5( \pm 10.5)$ & $P<0.01$ \\
\hline Ethnicity Caucasian yes/no/NA & $310 / 50 / 8$ & $263 / 16 / 4$ & $P<0.01$ \\
\hline Reported comorbid autoimmune disorder yes/no/NA & $3 / 187 / 178$ & 9/177/97 & $P=0.072$ \\
\hline ANAs positive/negative & $29(8 \%) / 339(92 \%)$ & $32(11 \%) / 251(89 \%)$ & $P=0.137$ \\
\hline Anti-PCNA & 1 & 1 & \\
\hline Anti-SSA & 1 & 1 & \\
\hline Anti-mitochondrial M2 & 0 & 1 & \\
\hline \multicolumn{4}{|c|}{$\begin{array}{l}\text { Abbreviations: ANA, antinuclear antibody; F, female; } M \text {, male; NA, not applicable. } \\
\text { aDiagnosis: } 295 \text { schizophrenia, } 58 \text { schizoaffective disorder, } 15 \text { schizophreniform disorder. Mean duration of illness } 7.3 \text { years }( \pm 4.3) \text {, range } 2-43 \text { years. Using } \\
\text { antipsychotics y/n/NA: } 257 / 37 / 74 \text {. Clozapine: } 58 \text {, olanzapine: } 54 \text {, risperidone: } 29 \text {, aripiprazol: } 27 \text {, quetiapine: } 15 \text {, haloperidol: } 12, \text { flupentixol: } 4, z u c l o p e n t h i x o l: ~ 4, \\
\text { bromperidol: } 2 \text {, pimozide: } 2 \text {, multiple antipsychotics: } 41 \text { and not specified antipsychotics: } 9 \text {. }\end{array}$} \\
\hline
\end{tabular}


Table 2. Overview of case-control studies on the prevalence of ANAs in patients with schizophrenia spectrum disorders

\begin{tabular}{|c|c|c|c|c|c|}
\hline Reference & Patients & ANA positive/\% & Controls & ANA positive/\% & ANA test \\
\hline Zarrabi et al. ${ }^{18}$ & 74 patients with schizophrenia & $29 / 39.2 \%$ & 15 & $0 / 0 \%$ & IF \\
\hline Yannitsi et al. ${ }^{17}$ & 179 patients with schizophrenia & $86 / 48.0 \%$ & 150 & $10 / 6.7 \%$ & IF on HEp-2 cells \\
\hline Ganguli et al. ${ }^{24}$ & 225 patients with schizophrenia or schizoaffective disorder & $30 / 13.3 \%$ & 327 & $20 / 6.1 \%$ & IF on HEp-2 cells \\
\hline Sirota et al. ${ }^{25}$ & 108 patients with schizophrenia & $42 / 38.9 \%$ & 210 & $8 / 3.8 \%$ & ELISA \\
\hline Laske et $a l^{28}$ & 34 patients with schizophrenia & $2 / 5.9 \%$ & 50 & $0 / 0 \%$ & IF on rat liver \\
\hline Sidhom et al. $^{29}$ & 60 patients with schizophrenia or schizoaffective disorder & $7 / 11.6 \%$ & 41 & $5 / 12.2 \%$ & IF on rat tissue \\
\hline
\end{tabular}

ANA positivity can be caused by antibodies with a wide variety of fine specificities. Only a part of these antibodies are well described and have clinically relevant associations with specific autoimmune disorders. ${ }^{3}$ A common way to detect fine specificity of ANAs is by line blot techniques. The method we used can detect reactivity against 14 antigens. The frequency of a positive result with line blot in the ANA-positive samples was low and no clinically relevant results were found. Most importantly, frequencies of positive results were similar for patients and control subjects.

In conclusion, our study shows that the prevalence of ANAs, with determination of specific antibodies, is similar in patients with a schizophrenia spectrum disorder and healthy controls. Our study suggests that previous findings on autoantibodies in schizophrenia should be interpreted with care, paying attention to potential confounders, and that further validation in large cohorts is needed before conclusions can be drawn.

\section{ACKNOWLEDGMENTS}

We are grateful for the generosity of time and effort by the patients and healthy subjects, and all researchers who make the GROUP project possible.

\section{CONTRIBUTIONS}

All authors contributed to and have approved the final manuscript. LdW and RS Kahn designed and supervised the study. HCvM analyzed the data, interpreted the results, and wrote the first draft of the manuscript. RHWMD and HGO contributed to the interpretation of the results and to the completion of the manuscript. GROUP Investigators designed the GROUP project and revised the manuscript.

\section{COMPETING INTERESTS}

The authors declare no conflict of interest.

\section{FUNDING}

The infrastructure for the GROUP study is funded through the Geestkracht program of the Dutch Health Research Council (ZON-MW, grant number 10-000-1001), and matching funds from participating pharmaceutical companies (Lundbeck, AstraZeneca, Eli Lilly, Janssen Cilag) and universities and mental health care organizations. (Amsterdam: Academic Psychiatric Centre of the Academic Medical Centre and the mental health institutions: GGZ Ingeest, Arkin, Dijk en Duin, GGZ Rivierduinen, Erasmus Medical Centre, GGZ Noord Holland Noord. Maastricht: Maastricht University Medical Centre and the mental health institutions: GGZ Eindhoven en de kempen, GGZ Breburg, GGZ Oost-Brabant, Vincent van Gogh voor Geestelijke Gezondheid, Mondriaan Zorggroep, Prins Clauscentrum Sittard, RIAGG Roermond, Universitair Centrum Sint-Jozef Kortenberg, CAPRI University of Antwerp, PC Ziekeren SintTruiden, PZ Sancta Maria Sint-Truiden, GGZ Overpelt, OPZ Rekem. Groningen: University Medical Centre Groningen and the mental health institutions: Lentis, GGZ Friesland, GGZ Drenthe, Dimence, Mediant, GGNet Warnsveld, Yulius Dordrecht and
Parnassia psycho-medical centre (The Hague). Utrecht: University Medical Centre Utrecht and the mental health institutions Altrecht, GGZ Centraal, Riagg Amersfoort and Delta).

\section{GENETIC RISK AND OUTCOME OF PSYCHOSIS (GROUP) INVESTIGATORS}

Richard Bruggeman ${ }^{1}$, Wiepke Cahn², Lieuwe de Haan ${ }^{3}$, René S. Kahn², Carin J. Meijer ${ }^{3}$, Inez Myin-Germeys ${ }^{4}$, Jim van Os ${ }^{4}$, Durk Wiersma ${ }^{1}$

${ }^{1}$ University Medical Center Groningen, Department of Psychiatry, University of Groningen, The Netherlands; ${ }^{2}$ University Medical Center Utrecht, Department of Psychiatry, Brain Center Rudolf Magnus, The Netherlands; ${ }^{3}$ Academic Medical Center University of Amsterdam, Department of Psychiatry, Amsterdam, The Netherlands; ${ }^{4}$ Maastricht University Medical Center, South Limburg Mental Health Research and Teaching Network, EURON, Maastricht, The Netherlands

\section{REFERENCES}

1 Benros ME, Eaton WW, Mortensen PB. The epidemiologic evidence linking autoimmune diseases and psychosis. Biol Psychiatry 2013; 75: 300-306.

2 Ezeoke A, Mellor A, Buckley P, Miller B. A systematic, quantitative review of blood autoantibodies in schizophrenia. Schizophr Res 2013; 150: 245-251.

3 Agmon-Levin N, Damoiseaux J, Kallenberg C, Sack U, Witte T, Herold M et al. International recommendations for the assessment of autoantibodies to cellular antigens referred to as anti-nuclear antibodies. Ann Rheum Dis 2014; 73: 17-23.

4 Holborow EJ, Weir DM, Johnson GD. A serum factor in lupus erythematosus with affinity for tissue nuclei. Br Med J 1957; 2: 732-734.

5 Ceppellini R, Polli E, Celada F. A DNA-reacting factor in serum of a patient with lupus erythematosus diffusus. Proc Soc Exp Biol Med 1957; 96: 572-574.

6 Tan EM, Kunkel HG. Characteristics of a soluble nuclear antigen precipitating with sera of patients with systemic lupus erythematosus. J Immunol 1966; 96: 464-471.

7 Abeles AM, Abeles M. The clinical utility of a positive antinuclear antibody test result. Am J Med 2013; 126: 342-348.

8 Liberal R, Mieli-Vergani G, Vergani D. Clinical significance of autoantibodies in autoimmune hepatitis. J Autoimmun 2013; 46: 17-24.

9 Solomon $\mathrm{DH}$, Kavanaugh AJ, Schur PH. Evidence-based guidelines for the use of immunologic tests: antinuclear antibody testing. Arthritis Rheum 2002; 47: 434-444.

10 Satoh M, Chan EK, Ho LA, Rose KM, Parks CG, Cohn RD et al. Prevalence and sociodemographic correlates of antinuclear antibodies in the United States. Arthritis Rheum 2012; 64: 2319-2327.

11 Korver N, Quee PJ, Boos HB, Simons CJ, de Haan L. Genetic Risk and Outcome of Psychosis (GROUP), a multi-site longitudinal cohort study focused on geneenvironment interaction: objectives, sample characteristics, recruitment and assessment methods. Int J Methods Psychiatr Res 2012; 21: 205-221.

12 Andreasen NC, Flaum M, Arndt S. The Comprehensive Assessment of Symptoms and History (CASH). An instrument for assessing diagnosis and psychopathology. Arch Gen Psychiatry 1992; 49: 615-623.

13 Wing JK, Babor T, Brugha T, Burke J, Cooper JE, Giel R et al. SCAN. Schedules for Clinical Assessment in Neuropsychiatry. Arch Gen Psychiatry 1990; 47: 589-593.

14 Berglund S, Gottfries CG, Gottfries I, Stormby K. Chlorpromazine-induced antinuclear factors. Acta Med Scand 1970; 187: 67-74. 
15 Canoso RT, de Oliveira RM, Nixon RA. Neuroleptic-associated autoantibodies. A prevalence study. Biol Psychiatry 1990; 27: 863-870.

16 Quismorio FP, Bjarnason DF, Kiely WF, Dubois EL, Friou GJ. Antinuclear antibodies in chronic psychotic patients treated with chlorpromazine. Am J Psychiatry 1975; 132: 1204-1206.

17 Yannitsi SG, Manoussakis MN, Mavridis AK, Tzioufas AG, Loukas SB, Plataris GK et al. Factors related to the presence of autoantibodies in patients with chronic mental disorders. Biol Psychiatry 1990; 27: 747-756.

18 Zarrabi MH, Zucker S, Miller F, Derman RM, Romano GS, Hartnett JA et al. Immunologic and coagulation disorders in chlorpromazine-treated patients. Ann Intern Med 1979; 91: 194-199.

19 Canoso RT, de Oliveira RM. Characterization and antigenic specificity of chlorpromazine-induced antinuclear antibodies. J Lab Clin Med 1986; 108: 213-216.

20 Canoso RT, Sise HS. Chlorpromazine-induced lupus anticoagulant and associated immunologic abnormalities. Am J Hematol 1982; 13: 121-129.

21 The Medicines Evaluation Board of the Netherlands. Intrekking Largactil tabletten en injectie. http://www.cbg-meb.nl/CBG/nl/humane-geneesmiddelen/actueel/ 20071108_Largactil/default.htm. Accessed on 8 January 2008.

22 Gottfries CG, Gottfries I. Antinuclear factors in relation to age, sex, mental disease and treatment with phenothiazines. Acta Psychiatr Scand Suppl 1974; 255: 193-201.

23 Villemain F, Chatenoud L, Galinowski A, Homo-Delarche F, Ginestet D, Loo H et al. Aberrant T cell-mediated immunity in untreated schizophrenic patients: deficient interleukin-2 production. Am J Psychiatry 1989; 146: 609-616.
24 Ganguli R, Rabin BS, Brar JS. Antinuclear and gastric parietal cell autoantibodies in schizophrenic patients. Biol Psychiatry 1992; 32: 735-738.

25 Sirota P, Firer MA, Schild K, Tanay A, Elizur A, Meytes D et al. Autoantibodies to DNA in multicase families with schizophrenia. Biol Psychiatry 1993; 33: 450-455.

26 Spivak B, Radwan M, Bartur P, Mester R, Weizman A. Antinuclear autoantibodies in chronic schizophrenia. Acta Psychiatr Scand 1995; 92: 266-269.

27 Zorrilla EP, Cannon TD, Gur RE, Kessler J. Leukocytes and organ-nonspecific autoantibodies in schizophrenics and their siblings: markers of vulnerability or disease? Biol Psychiatry 1996; 40: 825-833.

28 Laske C, Zank M, Klein R, Stransky E, Batra A, Buchkremer G et al. Autoantibody reactivity in serum of patients with major depression, schizophrenia and healthy controls. Psychiatry Res 2008; 158: 83-86.

29 Sidhom O, Laadhar L, Zitouni M, Ben AN, Rafrafi R, Kallel-Sellami M et al. Spectrum of autoantibodies in Tunisian psychiatric inpatients. Immunol Invest 2012; 41: 538-549.

(i) $\Theta$ This work is licensed under a Creative Commons Attributioncc) NonCommercial-NoDerivatives 4.0 International License. The images or other third party material in this article are included in the article's Creative Commons license, unless indicated otherwise in the credit line; if the material is not included under the Creative Commons license, users will need to obtain permission from the license holder to reproduce the material. To view a copy of this license, visit http:// creativecommons.org/licenses/by-nc-nd/4.0/ 